\title{
PRODUÇÃO E CARACTERÍSTICAS FÍSICO-QUÍMICAS DOS CACHOS DA VIDEIRA 'BRS CLARA' SOB COBERTURA PLÁSTICA E SOMBRITE EM SAFRA FORA DE ÉPOCA ${ }^{1}$

\author{
LILIAN YUKARI YAMAMOTO ${ }^{2}$, ADRIANE MARINHO DE ASSIS ${ }^{3}$, HEVERLY MORAIS $^{4}$, \\ FÁBIO SUANO DE SOUZA ${ }^{5}$, CLAUDIA REGINA SCAPIN ${ }^{6}$, DAURI JOSÉ TESSMANN ${ }^{7}$, \\ REGINALDO TEODORO DE SOUZA ${ }^{8}$, SÉRGIO RUFFO ROBERTO ${ }^{9}$
}

RESUMO - Devido às condições climáticas favoráveis à ocorrência de doenças fúngicas em uvas de mesa, tem-se buscado a adoção de tecnologias que propiciem a redução nos custos de produção, sendo uma alternativa o cultivo de uvas sob cobertura plástica. O objetivo deste trabalho foi avaliar a produção e as características físico-químicas dos cachos da videira 'BRS Clara' enxertada sobre o porta-enxerto IAC-766 'Campinas', em cultivo protegido durante a safra fora de época, visando à redução da aplicação de fungicidas para o controle do míldio. Os experimentos foram realizados em pomares comerciais localizados em Uraí e Marialva-PR. As videiras foram conduzidas no sistema latada, em espaçamento de 4,0 x 4,0 m, em Uraí, e de 2,0 x 5,0 m, em Marialva. O delineamento experimental foi o inteiramente casualizado, com dois sistemas de cultivo protegido (sob cobertura plástica e sob sombrite) e sete repetições. No experimento conduzido em Uraí, não foram verificadas diferenças entre os sistemas de cultivo protegido quanto às características produtivas e químicas das bagas, como o teor de sólidos solúveis totais, índice de maturação e pH. Verificou-se a ocorrência do míldio somente nas folhas, sendo a incidência e a severidade menor nas videiras sob cobertura plástica $(0,5$ e $0,02 \%$, respectivamente). Em Marialva, também não houve influência das coberturas nas características produtivas das videiras. Entretanto, o teor de sólidos solúveis totais das bagas sob cobertura plástica foi superior em relação àquelas sob sombrite $\left(19,6\right.$ e 17,2 ${ }^{\circ}$ Brix, respectivamente). Não foi detectada a ocorrência de míldio em nenhum dos sistemas de cultivo protegido nessa localidade. Conclui-se que o uso da cobertura plástica permite a redução do número de aplicações de fungicidas para o controle do míldio, sem alterar as características produtivas da uva 'BRS Clara'.

Termos para indexação: viticultura, uva apirena, cultivo protegido, maturação, produtividade.

\section{PRODUCTION AND PHYSICO-CHEMICAL CHARACTERISTICS OF BUNCHES OF 'BRS CLARA' GRAPEVINE UNDER PLASTIC COVER AND PLASTIC SCREEN GROWN OUT OF SEASON}

\begin{abstract}
Due to favorable climatic conditions for the occurrence of fungal diseases in table grapes, technologies that provides the reduction of production costs have been persuaded, and an alternative for it is the cultivation of grapes under plastic cover. The aim of this study was to evaluate the production and the bunches physico-chemical characteristics of the 'BRS Clara' grapevines grafted on IAC-766 'Campinas' rootstock, in protected cultivation during out of season crop, in order to reduce the application of fungicides to control downy mildew. The experiments were performed in commercial vineyards located at Uraí and Marialva, PR. The vines were trained in an over-head trellis system, in a spacing of $4.0 \times 4.0 \mathrm{~m}$ in Uraí, and $2.0 \times 5.0 \mathrm{~m}$ in Marialva. The randomized design was used as a statistical model, consisted of two protected cultivation (under plastic cover and under plastic screen) with seven replications. In the experiment conducted in Uraí, it was not verified difference between the protected cultivation systems regarding the grapevine production characteristics and chemical characteristics of the berries, such as soluble solids content, maturation index and $\mathrm{pH}$. It was verified the occurrence of downy mildew just on leaves, which the incidence and severity was lower in vines under plastic cover ( 0.5 and $0.02 \%$ respectively). In Marialva, the plastic cover had no influence on grape production characteristics as well. However, the soluble solids content of berries under plastic cover was higher in relation to those under plastic screen (19.6 and $17.2^{\circ} \mathrm{Brix}$, respectively). It was not detected the occurrence of downy mildew in any of the systems of protected cultivation in this location. It was concluded that the use of plastic cover allows the reduction of the number of fungicide applications to control downy mildew, with no change on production characeristics of 'BRS Clara' grape.
\end{abstract}

Index terms: Viticulture, seedless grape, protected cultivation, ripening, production.

\footnotetext{
'Trabalho 148-11). Recebido em: 13-05-2011. Aceito para publicação em: 04-01-2012 Parte da Dissertação de Mestrado em Fitotecnia do primeiro autor, Universidade Estadual de Londrina).

${ }^{2}$ Eng. Agr., M. Sc., Universidade Estadual de Londrina, Bolsista CNPq. lilianyamamoto@yahoo.com.br

${ }^{3}$ Eng. Agr., Dr., UEL, Londrina-PR, Bolsista PNPD/Capes. E-mail: agroadri@ig.com.br

${ }^{4}$ Eng. Agr., Dr., Pesquisador, Instituto Agronomico do Paraná. E-mail: heverlymorais@gmail.com

${ }^{5}$ Eng. Agr., Dr., Prof., Centro Universitário Filadélfia. E-mail: fabio.suano@unifil.br

${ }^{6}$ Eng. Agr., M. Sc., Universidade Estadual de Maringá. E-mail: claudiascapin@hotmail.com

${ }^{7}$ Eng. Agr., Dr., Prof. Associado, Depto de Agronomia. Universidade Estadual de Maringá.E-mail: djtessmann@uem.br

${ }^{8}$ Eng. Agr., Dr., Pesquisador, Embrapa Uva e Vinho. E-mail: recco@melfinet.com.br

${ }^{9}$ Eng. Agr., Dr., Prof. Associado, Depto de Agronomia/Fitotecnia, Universidade Estadual de Londrina, Bolsista do CNPq. E-mail sroberto@uel.br
} 


\section{INTRODUÇÃO}

No Paraná, o cultivo da videira concentra-se nas regiões norte e noroeste do Estado, que apresentam relevante importância quanto ao abastecimento do mercado interno de uvas para consumo dos frutos in natura, produzindo tradicionalmente as uvas 'Itália', 'Rubi', 'Benitaka' e 'Brasil' (KISHINO et al., 2007). No entanto, nos últimos anos, têm-se verificado algumas mudanças no sistema produtivo destas regiões, com a introdução de novas cultivares, dentre a quais se destacam as uvas sem sementes.

A 'BRS Clara' é vigorosa e fértil, com suave e agradável sabor moscatel, coloração verde-amarelada e textura crocante da polpa (CAMARGO et al., 2003). Esta cultivar vem despertando o interesse dos viticultores do norte do Paraná, onde o cultivo se diferencia das demais regiões em função da dupla poda anual, que permite a colheita da primeira safra de dezembro a janeiro, e a segunda produção, denominada de safra fora de época, de maio a junho, período em que a oferta de uvas de mesa no Brasil, em outras regiões, é baixa ou inexistente (KISHINO et al., 2007). Entretanto, principalmente durante a safra fora de época, boa parte do ciclo produtivo da videira ocorre no período chuvoso, quando a temperatura e a umidade relativa do ar são mais elevadas. Tais condições são propícias à ocorrência de doenças fúngicas, que se tornam fator limitante à viticultura, caso medidas adequadas de controle não sejam adotadas (NAVES et al., 2005; KISHINO et al., 2007; COLOMBO, 2010).

Para minimizar este problema, uma alternativa é o emprego do sistema de produção de uvas sob cobertura plástica, que apresenta como principais vantagens a redução dos tratamentos fitossanitários, a obtenção de frutos de melhor qualidade, a economia de insumos e a conservação do solo, além da valorização comercial do produto, pela obtenção de colheitas fora de época (DETONI et al., 2007).

Vários estudos vêm sendo realizados no intuito de averiguar a eficácia deste sistema no cultivo das videiras em diferentes partes do mundo, com resultados satisfatórios quanto à redução da ocorrência de doenças e aplicação de fungicidas (LULU et al., 2005; DETONI et al., 2007; NOVELLO; PALMA, 2008; CHAVARRIA et al., 2010; COLOMBO et al., 2011; GENTA et al., 2010). Nas regiões norte e noroeste do Paraná, o cultivo de videiras é realizado com o uso de sombrite em mais de $95 \%$ das propriedades rurais (COLOMBO, 2010).

Diante do exposto, o objetivo deste trabalho foi avaliar a produção e as características físico- químicas dos cachos da videira 'BRS Clara' cultivada sob cobertura plástica, em safra fora de época, visando à redução do número de aplicações de produtos fitossanitários para o controle do míldio.

\section{MATERIAL E MÉTODOS}

O primeiro experimento foi conduzido de janeiro a maio de 2009, em um vinhedo localizado em Uraí-PR (latitude 2314'33,9' $\mathrm{S}$, longitude $50^{\circ} 46^{\prime} 55,5^{\prime \prime} \mathrm{W}$ e altitude $438 \mathrm{~m}$ ). O solo desta região é classificado como Nitossolo Vermelho eutroférrico e o clima é do tipo Cfa (Clima subtropical), segundo a classificação de Köeppen.

Foi avaliado o comportamento da uva 'BRS Clara', enxertada sobre o porta-enxerto IAC-766 'Campinas', sob cobertura plástica e sob sombrite. Efetuou-se o plantio do porta-enxerto e a enxertia da variedade copa, em julho de 2004 e de 2005, respectivamente, utilizando-se de material propagativo da Embrapa Uva e Vinho, Bento Gonçalves-RS. As videiras foram conduzidas no sistema latada, em espaçamento de 4,0 x 4,0 m.

A poda longa de frutificação, deixando-se seis a oito gemas por vara, foi realizada no dia 14 de janeiro de 2009 e, em seguida, aplicou-se sobre as duas gemas apicais o regulador de crescimento cianamida hidrogenada a $2,5 \%$, para a uniformização da brotação. Foi aplicado ácido giberélico $\left(33 \mathrm{mg} \mathrm{L}^{-1}\right)$ sobre os cachos, 20 dias após o florescimento, para promover o engrossamento do racimo e o aumento do tamanho da baga.

No sistema de cultivo protegido com cobertura plástica, foram utilizadas lonas plásticas transparentes de polietileno trançado $(20 \%$ de sombreamento), com 5,0 m de largura e 150 micras de espessura, aditivadas contra raios ultravioleta e antigotejo, modelo TEC 5000 (Terra Toledo Coberturas, Caxias do Sul-RS). A cobertura plástica foi instalada em 2008 sobre fios metálicos e arcos de ferro galvanizado de $5,0 \mathrm{~m}$, dispostos no parreiral a cada 3,0 m, que, por sua vez, foram fixados sobre a estrutura de postes de eucalipto, que propicia sustentação e forma ao sistema de condução. O ponto mais alto da cobertura plástica ficou a uma distância de $1,2 \mathrm{~m}$ em relação às videiras. As cortinas laterais da área do experimento foram mantidas com sombrite.

Nas videiras cultivadas sob sombrite, no sistema de capela, utilizou-se tela de polietileno preta, com $23 \%$ de retenção de fluxo de radiação solar, sustentada pelos fios de arame da latada, sem a utilização de arcos.

A irrigação por aspersão (realizada abaixo da copa das videiras) e os tratos culturais foram 
efetuados de acordo com as recomendações técnicas para a região (KISHINO et al., 2007). Com relação às aplicações de produtos fitossanitários, foram realizadas 16 e 39 aplicações para o controle do míldio nas videiras cultivadas sob cobertura plástica e sob sombrite, respectivamente, de acordo com o critério do consultor que assiste a área. As aplicações foram realizadas no início da brotação e estenderam-se até 20 dias antes da colheita.

O segundo experimento foi realizado no período de janeiro a maio de 2010 , em um vinhedo localizado em Marialva-PR (latitude 2329' 52,8' ' S, longitude $51^{\circ} 47^{\prime} 58,0^{\prime \prime} \mathrm{W}$ e altitude $570 \mathrm{~m}$ ). O solo desta região é classificado como Nitossolo Vermelho eutroférrico e o clima é do tipo Cfa (Clima subtropical), segundo a classificação de Köeppen.

Foi avaliado o comportamento da uva 'BRS Clara', enxertada sobre o porta-enxerto IAC-766 'Campinas', sob cobertura plástica e sob sombrite. Efetuaram-se o plantio do porta-enxerto e a enxertia da variedade copa em julho de 2003 e 2004, respectivamente, utilizando-se de material propagativo da Embrapa Uva e Vinho, Bento Gonçalves-RS. As videiras foram conduzidas no sistema latada, em espaçamento de 2,0 x 5,0 m.

A poda longa de frutificação, deixando-se seis a oito gemas por vara, foi realizada no dia 13 de janeiro de 2010, e em seguida foi aplicado cianamida hidrogenada a $2,5 \%$ sobre as duas gemas apicais. Foi aplicado ácido giberélico $\left(50 \mathrm{mg} \mathrm{L}^{-1}\right)$ sobre os cachos 20 dias após o florescimento, sendo reaplicado cinco dias após.

No sistema de cultivo protegido com cobertura plástica, foi utilizado o mesmo material do experimento realizado em Uraí, sendo instalado no mesmo período, diferindo somente nas dimensões da cobertura para ajuste ao espaçamento da cultura. A largura da cobertura foi de $3,0 \mathrm{~m}$, e o comprimento dos arcos de ferro galvanizado foi de 3,0 m, dispostos no parreiral a cada $2,5 \mathrm{~m}$, totalizando sete fileiras. $\mathrm{O}$ ponto mais alto da cobertura plástica ficou a uma distância de $0,90 \mathrm{~m}$ em relação às videiras.

Nas plantas cultivadas sob sombrite, no sistema de capela, utilizou-se tela de polietileno preta com $18 \%$ de retenção de fluxo de radiação solar, sustentada pelos fios de arame do sistema latada, sem a utilização de arcos.

Para a determinação da irrigação e dos tratos culturais, foi usado o mesmo critério do experimento realizado em Uraí. Com relação às aplicações de produtos fitossanitários, foram realizadas 16 e 78 aplicações para o controle do míldio nas videiras cultivadas sob cobertura plástica e sombrite, respectivamente, de acordo com o critério do consultor que assiste a área.
As aplicações foram realizadas no início da brotação e estenderam-se até 20 dias antes da colheita.

Durante a condução dos experimentos, foram obtidos valores médios de temperatura de 19,3 e $21,9^{\circ} \mathrm{C}$, umidade relativa do ar de 82,3 e $81,5 \%$, e precipitação de 704,3 e 633,4 mm, em Uraí e em Marialva, respectivamente.

No início do ciclo reprodutivo, em ambas as áreas experimentais, foram registras a porcentagem de gemas brotadas por planta e a fertilidade de gemas (\%). Para tanto, foram selecionadas sete videiras representativas em cada sistema de cultivo protegido.

As características químicas das bagas, como teor de sólidos solúveis totais (SST), acidez titulável (AT), índice de maturação (SST/AT) e pH, foram avaliadas no momento da colheita. Foram marcados dez cachos representativos em cada planta, sendo retiradas uma baga da parte superior, mediana e inferior do cacho, totalizando 30 bagas por planta. A colheita foi realizada com base no teor de SST, bem como no valor de mercado do produto.

O teor de SST foi determinado em refratômetro digital de bancada, com compensação automática de temperatura (Modelo DR301-95, Krüss Optronic, Alemanha), após a trituração das amostras, e o resultado foi expresso em ${ }^{\circ}$ Brix. A determinação da AT e do $\mathrm{pH}$ foi realizada por titulação do suco com solução padronizada de $\mathrm{NaOH} 0,1 \mathrm{~N}$ em titulador potenciométrico digital (Modelo Tritoline Easy, Schott Geräte, Alemanha), adotando-se como ponto final da titulação o $\mathrm{pH}=8,2$, e o resultado, expresso em porcentagem de ácido tartárico.

Por ocasião da colheita, foi registrado o número de cachos por planta e por $\mathrm{m}^{2}$, e a massa (kg) de dez cachos por repetição, sendo estimadas a produção por planta (kg por planta) e a produtividade $\left(\mathrm{t} \mathrm{ha}^{-1}\right)$. Os cachos foram colhidos com o auxílio de tesoura de poda e submetidos à limpeza, eliminandose as bagas danificadas. A massa dos cachos foi determinada em balança digital.

A incidência (presença ou ausência de doença) e a severidade (porcentagem de área foliar doente) do míldio (Plasmopara viticola) foram avaliadas utilizando-se a escala descritiva de Horsfall-Barratt, reproduzida em Campbell e Madden (1990). As avaliações foram realizadas nas folhas e nos cachos das videiras, por amostragem de quatro ramos marcados em cada repetição, duas semanas antes da colheita.

O delineamento experimental utilizado foi o inteiramente casualizado, com dois tratamentos e sete repetições. Os dados de incidência e severidade do míldio, bem como das características físicoquímicas e da produção de cada safra foram submetidos à análise, pelo teste t de Student para amostras 
independentes, a 5\% de significância.

\section{RESULTADOS E DISCUSSÃO}

Não houve diferença entre os sistemas de cultivo protegido com relação à porcentagem de gemas brotadas por planta e à fertilidade de gemas nos vinhedos localizados em Uraí e Marialva-PR (Tabela 1). Esses resultados estão de acordo com Colombo (2010), que não verificou diferença quanto a essas variáveis para a videira 'BRS Clara', em Marialva-PR.

Em estudo com a 'Cabernet Sauvignon', cultivada com e sem cobertura plástica em Caxias do Sul-RS, Mota et al. (2008) não observaram diferença quanto à porcentagem de gemas brotadas, relatando que o microclima no interior da cobertura plástica não comprometeu o potencial de diferenciação de gemas e, consequentemente, a fertilidade de gemas.

Quanto ao número de cachos por planta e por $\mathrm{m}^{2}$, não houve diferença significativa entre os tipos de cultivo protegido em ambas as áreas experimentais (Tabela 1). No experimento realizado em Uraí-PR, o número de cachos por $\mathrm{m}^{2}$ foi superior à recomendação para esta cultivar, que é de 3 a 4 cachos por $\mathrm{m}^{2}$ (SOUZA, 2010), estando os valores obtidos no experimento realizado em Marialva-PR, dentro dessa faixa.

Da mesma forma, Colombo et al. (2011) observaram que o cultivo da videira 'BRS Clara' sob sombrite (aplicação-padrão de fungicidas) e sob cobertura plástica (com redução de 50 e $75 \%$ da aplicação-padrão de fungicidas) não exerceram influência sobre o número de cachos por planta, em Marialva-PR. Mota et al. (2008), avaliando a videira 'Cabernet Sauvignon', em Caxias do Sul$\mathrm{RS}$, descreveram que as condições microclimáticas no interior da cobertura plástica não interferiram no número de cachos por planta. No entanto, Chavarria et al. (2009) constataram maior número de cachos por planta e por $\mathrm{m}^{2}$ nas videiras 'Moscato Giallo' sob cobertura plástica, em Flores da Cunha-RS. Tal fato pode ter ocorrido em função da cultivar utilizada, do número de varas deixadas por planta e das condições climáticas de cada região, visto que exercem influência direta na fertilidade das gemas e, consequentemente, na produção de cachos por planta.

Para a massa dos cachos, não houve diferença significativa entre os sistemas de cultivo protegido nas duas áreas experimentais (Tabela 1), registrando-se valores inferiores aos apontados por Souza (2010) para o cultivo da 'BRS Clara', no norte e noroeste do Paraná (em torno de 0,5 a 0,7 kg). Em estudo realizado por Colombo et al. (2011), com a mesma cultivar, não houve diferença entre as videiras cultivadas sob sombrite e sob cobertura plástica para a massa dos cachos. Mota et al. (2008) e Chavarria et al. (2009), trabalhando com as videiras 'Cabernet Sauvignon' e 'Moscato Giallo', respectivamente, também não constataram diferença na massa dos cachos entre as plantas cultivadas sob cobertura plástica e a céu aberto.

No que se refere à estimativa de produção e de produtividade, não houve diferença significativa entre os sistemas de cultivo protegido nos dois vinhedos avaliados (Tabela 1).

De modo semelhante, Colombo et al. (2011) concluíram que não houve diferença na produção e na produtividade da videira 'BRS Clara' cultivada sob sombrite e sob cobertura plástica, em Marialva-PR. Mota et al. (2008) e Ferreira et al. (2004), trabalhando com a uva 'Cabernet Sauvignon' em Caxias do Sul-RS e Jundiaí-SP, respectivamente, não observaram diferenças com relação à produção e produtividade entre a área com e sem cobertura plástica. Por outro lado, Detoni et al. (2007) verificaram valores superiores sob a cobertura plástica para a mesma cultivar, em Toledo-PR. Chavarria et al. (2009) também registraram maior produção por planta e produtividade da uva 'Moscato Giallo', em Flores da Cunha-RS, na área coberta com plástico. Entretanto, ressalta-se que a produção das videiras não é influenciada somente pelo tipo de cobertura, mas envolve também vários fatores, como: características da variedade e do porta-enxerto, sistemas de condução, tipos de poda, fertilidade do solo, práticas culturais utilizadas em cada região e condições edafoclimáticas.

Para o teor de sólidos solúveis totais (SST) no momento da colheita, não houve diferença significativa entre as videiras cultivadas sob cobertura plástica $\left(17,6^{\circ} \mathrm{Brix}\right)$ e sob sombrite $\left(16,4^{\circ} \mathrm{Brix}\right)$, em Uraí-PR. No vinhedo de Marialva-PR, o teor de SST foi superior nas videiras sob cobertura plástica $\left(19,6^{\circ} \mathrm{Brix}\right) \mathrm{em}$ relação ao sombrite $\left(17,2^{\circ}\right.$ Brix $)$ (Tabela 1$)$.

Segundo Souza (2010), os cachos da cultivar BRS Clara podem atingir em torno de $19,0^{\circ}$ Brix durante a colheita, valor este verificado no presente trabalho, nas videiras sob cobertura plástica, em Marialva-PR. Embora as demais médias obtidas em ambos os vinhedos sejam um pouco inferiores, tais valores foram superiores ao mínimo estabelecido para a comercialização de uvas finas de mesa do grupo 'Itália', que é de $14,0^{\circ}$ Brix (BRASIL, 2002). No entanto, Souza (2010) descreve que o teor de SST entre 13,0 e $14,0^{\circ}$ Brix é inadequado para o consumo da 'BRS Clara', em função da elevada acidez e sabor adstringente acentuado dos frutos. 
Em experimento realizado por Colombo (2010), a cobertura plástica e o sombrite não influenciaram no teor de SST da videira 'BRS Clara', em Marialva-PR. De modo semelhante, Lulu et al. (2005), Detoni et al. (2007) e Chavarria et al. (2010) não verificaram diferença significativa no teor de SST da uva 'Romana' (A 1105), 'Cabernet Sauvignon' e 'Moscato Giallo', respectivamente, cultivadas sob cobertura plástica e a céu aberto.

Quanto ao teor de acidez titulável (AT) no momento da colheita, as uvas cultivadas em Uraí$\mathrm{PR}$, sob cobertura plástica apresentaram maior média $(0,7 \%)$, quando comparadas sob sombrite $(0,6 \%)$ (Tabela 1); no entanto, essa diferença não refletiu no índice de maturação. Com relação ao vinhedo localizado em Marialva-PR, não houve diferença significativa para esta variável entre os tipos de cultivo protegido, concordando com Colombo (2010). Da mesma forma, Chavarria et al. (2010) relataram que não houve diferença no teor de $\mathrm{AT}$ das uvas de 'Moscato Giallo' cultivadas em Flores da Cunha-RS, nas áreas coberta e descoberta.

O índice de maturação (SST/AT) não diferiu nos dois municípios entre os sistemas de cultivo protegido, registrando-se, em média, 23,6 e 25,7, respectivamente, sob cobertura plástica e sombrite, no vinhedo em Uraí-PR, e 26,2 e 23,3 em Marialva-PR (Tabela 1). Conforme Camargo et al. (2003), a 'BRS Clara' apresenta elevado potencial glucométrico, chegando a mais de $20,0^{\circ}$ Brix, sendo o índice de maturação em torno de 24,0 no momento da colheita. Resultado semelhante foi verificado por Colombo (2010) para essa variável na videira 'BRS Clara', em Marialva-PR. Schideck et al. (1999) também observaram o aumento do índice de maturação durante o processo de maturação da uva 'Niágara Rosada', em Bento Gonçalves-RS, com oscilações nos tratamentos a céu aberto, em função das precipitações pluviométricas.

Quanto ao $\mathrm{pH}$, não houve diferenças significativas entre os sistemas de cultivo protegido (Tabela 1) em Uraí-PR, registrando-se média de 3,4 . No vinhedo em Marialva-PR, o valor médio foi superior nas videiras cultivadas sob cobertura plástica $(3,5)$, em comparação às cultivadas sob sombrite $(3,4)$; contudo, essa diferença foi mínima e não interferiu na determinação do momento da colheita. Schiedeck et al. (1999), Detoni et al. (2007) e Chavarria et al. (2008) relataram valores de $\mathrm{pH}$ inferiores nas uvas sob cobertura plástica, em relação às cultivadas a céu aberto, indicando que a variação nos valores obtidos pode estar relacionada à cultivar utilizada.

No que diz respeito à incidência e à severidade de doenças, em Uraí-PR, foi verificada a ocorrência do míldio nas folhas das videiras nos dois sistemas de cultivo protegido (Tabela 2). Mesmo com a redução em 16 aplicações de produtos fitossanitários nas videiras cultivadas sob cobertura plástica, a incidência e a severidade desta doença foram menores em comparação às videiras sob sombrite. Esse resultado está relacionado à barreira física, à ação da chuva e aos raios ultravioletas promovidos pela cobertura plástica, o que, segundo Chavarria et al. (2007), pode impedir a lavagem e a degradação das moléculas dos produtos fitossanitários.

Em Marialva-PR, não foi constatada a ocorrência de doenças nas folhas e nos cachos das videiras, em ambos os ambientes, apesar das condições climáticas favoráveis. Este resultado está relacionado ao maior número de aplicações de produtos fitossanitários (78) realizado nesta área, o que proporcionou o controle efetivo do míldio. Apesar da redução do número de aplicações de produtos fitossanitários nas videiras cultivadas sob cobertura plástica (16), o controle da doença nesse sistema também foi efetivo. Colombo et al. (2011) e Genta et al. (2010) relataram que o emprego da cobertura plástica permite a redução de até $75 \%$ do número de aplicações de produtos fitossanitários, mas por si só não é suficiente para prevenir a ocorrência de míldio nos cachos, em condições de umidade elevada.

Conforme Naves et al. (2005) e Sônego et al. (2005), valores de umidade relativa do ar de $75 \%$, temperatura entre 20 e $25^{\circ} \mathrm{C}$ e presença de água livre na superfície dos tecidos vegetais são condições favoráveis para a ocorrência do míldio. Durante a condução dos experimentos em safra fora de época, as condições de temperatura e umidade relativa do ar estavam dentro da faixa ideal para a ocorrência de doenças fúngicas; no entanto, o uso da cobertura plástica proporcionou a redução da ocorrência de míldio. Lulu et al. (2005), Detoni et al. (2007) e Genta et al. (2010) também relataram a redução da ocorrência de doenças nas videiras cultivadas sob cobertura plástica.

Em síntese, pôde-se observar que, embora a safra fora de época de uvas ocorra no período favorável à ocorrência de doenças, como o míldio, em função das condições climáticas, a utilização da cobertura plástica propicia barreira física à ação da chuva e dos raios ultravioletas, permitindo reduzir o número de aplicações de produtos fitossanitários no cultivo da videira 'BRS Clara', sem alterar os níveis de produtividade. Desta forma, possibilita a redução nos custos de produção, devido ao menor gasto com defensivos químicos, mão de obra e maquinários, tornando a região mais competitiva no cultivo de uvas sem semente. Além disso, contribui para reduzir 
os eventuais danos que os produtos fitossanitários utilizados podem causar ao meio ambiente e aos colaboradores envolvidos em sua aplicação. No entanto, por se tratar de um novo sistema de produção de uvas de mesa, alguns fatores, como os custos de implantação e manutenção do plástico, devem ser considerados, pois, em média, a durabilidade deste material é de três anos, enquanto o sombrite tem durabilidade de 15 anos.

TABELA 1 - Características da brotação, dos cachos, da produção e da composição química das bagas da videira 'BRS Clara' sobre o porta-enxerto IAC-766 'Campinas', submetida a diferentes tipos de cultivo protegido. Uraí-PR, 2009 e Marialva-PR, 2010.

\begin{tabular}{|c|c|c|c|c|}
\hline Tipos de Cultivo Protegido & Plástico & Sombrite & $\mathrm{t}$ & $\mathrm{CV}(\%)$ \\
\hline & \multicolumn{4}{|c|}{ Uraí } \\
\hline$\%$ de gemas brotadas por planta & $100,0 \mathrm{a}$ & 99,9 a & $1,00 \mathrm{~ns}$ & 0,17 \\
\hline Fertilidade de gemas (\%) & 99,4 a & 98,6 a & $1,49 \mathrm{~ns}$ & 1,02 \\
\hline Número de cachos por planta & $112,0 \mathrm{a}$ & $115,3 \mathrm{a}$ & $-0,38 \mathrm{~ns}$ & 14,19 \\
\hline Número de cachos por $\mathbf{m}^{2}$ & $7,0 \mathrm{a}$ & $7,2 \mathrm{a}$ & $-0,39 \mathrm{~ns}$ & 14,21 \\
\hline Massa dos cachos (kg) & $0,4 \mathrm{a}$ & $0,4 \mathrm{a}$ & $-0,97 \mathrm{~ns}$ & 9,31 \\
\hline Produção (kg por planta)a/ & $47,1 \mathrm{a}$ & $51,0 \mathrm{a}$ & $-0,87 \mathrm{~ns}$ & 17,18 \\
\hline Produtividade $\left(\mathrm{t} \mathrm{ha}^{-1}\right)^{\mathrm{b} /}$ & $29,4 \mathrm{a}$ & $31,9 \mathrm{a}$ & $-0,87 \mathrm{~ns}$ & 17,18 \\
\hline SST $\left({ }^{\circ} \text { Brix }\right)^{\mathrm{c} /}$ & $17,6 \mathrm{a}$ & $16,4 \mathrm{a}$ & $1,81 \mathrm{~ns}$ & 6,86 \\
\hline AT (\% de ácido tartárico) ${ }^{\mathrm{d} /}$ & $0,7 \mathrm{a}$ & $0,6 \mathrm{~b}$ & $7,28 *$ & 4,07 \\
\hline SST/AT & $23,6 \mathrm{a}$ & $25,7 \mathrm{a}$ & $-1,98 \mathrm{~ns}$ & 7,85 \\
\hline \multirow[t]{2}{*}{ pH } & $3,4 \mathrm{a}$ & $3,4 \mathrm{a}$ & $-1,89 \mathrm{~ns}$ & 1,46 \\
\hline & \multicolumn{4}{|c|}{ Marialva } \\
\hline$\%$ de gemas brotadas por planta & $67,9 \mathrm{a}$ & $64,6 \mathrm{a}$ & $0,93 \mathrm{~ns}$ & 10,14 \\
\hline Fertilidade de gemas (\%) & $70,1 \mathrm{a}$ & $66,4 \mathrm{a}$ & $0,63 \mathrm{~ns}$ & 16,60 \\
\hline Número de cachos por planta & $47,2 \mathrm{a}$ & $44,4 \mathrm{a}$ & $0,31 \mathrm{~ns}$ & 38,15 \\
\hline Número de cachos por $\mathbf{m}^{2}$ & $4,7 \mathrm{a}$ & $4,4 \mathrm{a}$ & $0,31 \mathrm{~ns}$ & 38,15 \\
\hline Massa dos cachos (kg) & $0,3 \mathrm{a}$ & $0,3 \mathrm{a}$ & $1,72 \mathrm{~ns}$ & 14,98 \\
\hline Produção (kg por planta) a/ & $16,2 \mathrm{a}$ & $13,3 \mathrm{a}$ & $0,82 \mathrm{~ns}$ & 44,62 \\
\hline Produtividade $\left(\mathrm{t} \mathrm{ha}^{-1}\right)^{\mathrm{b} /}$ & $16,2 \mathrm{a}$ & $13,3 \mathrm{a}$ & $0,82 \mathrm{~ns}$ & 44,62 \\
\hline SST $\left({ }^{\circ} \text { Brix }\right)^{\mathrm{c} /}$ & $19,6 \mathrm{a}$ & $17,2 \mathrm{~b}$ & $3,87^{*}$ & 6,11 \\
\hline AT (\% de ácido tartárico $)^{\mathrm{d} /}$ & $0,7 \mathrm{a}$ & $0,7 \mathrm{a}$ & $-0,15 \mathrm{~ns}$ & 11,42 \\
\hline SST/AT & $26,2 \mathrm{a}$ & $23,3 \mathrm{a}$ & $1,83 \mathrm{~ns}$ & 11,93 \\
\hline pH & $3,5 \mathrm{a}$ & $3,4 \mathrm{~b}$ & $3,46^{*}$ & 1,40 \\
\hline
\end{tabular}

Médias seguidas da mesma letra nas linhas não diferem entre si, pelo teste $t$ de Student $(p<0,05)$. ns: não significativo. ${ }^{a /}$ : Estimativa em função do número médio de cachos por planta e da massa média dos cachos. ${ }^{\mathrm{b}}$ : Estimativa em função da produção média por planta $\mathrm{e}$ do número de plantas por hectare. ${ }^{\mathrm{c} /}$ : sólidos solúveis totais. ${ }^{\mathrm{d} /}$ : acidez titulável.

TABELA 2 - Incidência e severidade de míldio (Plasmopara viticola) nas folhas da videira 'BRS Clara' sobre o porta-enxerto IAC-766 'Campinas', submetida a diferentes tipos de cultivo protegido, duas semanas antes da colheita. Uraí-PR, 2009.

\begin{tabular}{ccccc}
\hline Tipos de Cultivo Protegido & Plástico & Sombrite & $\mathrm{t}$ & $\mathrm{CV}(\%)$ \\
Incidência (\%) & $0,5 \mathrm{~b}$ & $21,5 \mathrm{a}$ & $-7,37^{*}$ & 48,38 \\
Severidade (\%) & $0,02 \mathrm{~b}$ & $0,65 \mathrm{a}$ & $-4,75^{*}$ & 73,67 \\
\hline
\end{tabular}

Médias seguidas da mesma letra nas linhas não diferem entre si, pelo teste $\mathrm{t}$ de Student $(p<0,05)$. *: significativo $(p<0,05)$. 


\section{CONCLUSÃO}

A cobertura plástica pode ser utilizada no cultivo da videira 'BRS Clara' sem alterar suas principais características produtivas, resultando na redução da aplicação de fungicidas para o controle do míldio.

\section{REFERÊNCIAS}

CAMARGO, U. A.; NACHTIGAL, J. C.; MAIA, J. D. G.; OLIVEIRA, P. R. D.; PROTAS, J. F. S. BRS Clara: nova cultivar de uva branca de mesa sem semente. Bento Gonçalves: Embrapa Uva e Vinho, 2003. 4p. (Comunicado Técnico, 46).

CAMPBELL, C.L.; MADDEN, L.V. Introduction to plant disease epidemiology. New York: John Wiley, 1990. 532p.

CHAVARRIA, G.; SANTOS, H. P.; MANDELLI, F.; MARODIN, G. A. B.; BERGAMASCHI, H.; CARDOSO, L. S. Potencial produtivo de videiras cultivadas sob cobertura de plástico. Pesquisa Agropecuária Brasileira, Brasília, v.44, n.2, p.141-147, 2009.

CHAVARRIA, G.; SANTOS, H. P.; SÔNEGO, O. R.; MARODIN, G. A. B.; BERGAMASCHI, H.; CARDOSO, L. S. Incidência de doenças e necessidade de controle em cultivo protegido de videira. Revista Brasileira de Fruticultura, Jaboticabal, v.29, n.3, p.477-482, 2007.

CHAVARRIA, G.; SANTOS, H. P.; ZANUS, M. C.; MARODIN, G. A. B.; CHALAÇA, M.Z.; ZORZAN, C. Maturação de uvas Moscato Giallo sob cultivo protegido. Revista Brasileira de Fruticultura, Jaboticabal, v.32, n.1, p.151-160, 2010.

CHAVARRIA, G.; SANTOS, H. P.; ZANUS, M. C.; ZORZAN, C.; MARODIN, G. A. B. Caracterização físico-química do mosto e do vinho Moscato Giallo em videiras cultivadas sob cobertura de plástico. Pesquisa Agropecuária Brasileira, Brasília, v.43, n.7, p.911-916, 2008.

COLOMBO, L. A. Utilização da cobertura plástica no cultivo da uva sem semente 'BRS Clara'. 2010. $103 \mathrm{f}$. Tese (Doutorado em Fitotecnia) - Universidade Estadual de Londrina, Londrina, 2010.

COLOMBO, L. A.; ASSIS, A. M.; SATO, A. J.; TESSMANN, D. J.; GENTA, W.; ROBERTO, S. R. Produção fora de época da videira 'BRS Clara' sob cultivo protegido. Ciência Rural, Santa Maria. v.41, n.2, p.212-218, 2011

DETONI, A. M.; CLEMENTE, C.; FORNARI, C. Produtividade e qualidade da uva 'Cabernet Sauvig- non' produzida sob cobertura de plástico em cultivo orgânico. Revista Brasileira de Fruticultura, Jaboticabal, v.29, n.3, p.530-534, 2007.

FERREIRA, M. A.; PEDRO JÚNIOR, M. J.; SANTOS, A. O.; HERNANDES, J. L. Modificação parcial do ambiente de cultivo da videira 'Cabernet Sauvignon' sobre diferentes porta-enxertos: efeito sobre a produção e o teor de sólidos solúveis. Bragantia, Campinas, v.63, n.3, p.439-445, 2004

GENTA, W.; TESSMANN, D. J.; ROBERTO, S. R.; VIDA, J. B.; COLOMBO, L. A.; SCAPIN, C. R.; RICE, W. S.; CLOVIS, L. R. Manejo de míldio no cultivo protegido de videira de mesa 'BRS Clara'. Pesquisa Agropecuária Brasileira, Brasília, v.45, n.12, p.1388-1395, 2010.

KISHINO, A. Y.; CARVALHO, S. L. C.; ROBERTO, S. R. Viticultura tropical: o sistema de produção do Paraná. Londrina: IAPAR, 2007. 366p.

LULU, J.; CASTRO, J. V.; PEDRO JÚNIOR, M. J. Efeito do microclima na qualidade da uva de mesa 'Romana' (A 1105) cultivada sob cobertura plástica. Revista Brasileira de Fruticultura, Jaboticabal, v.27, n.3, p.422-425, 2005.

MOTA, C. S.; AMARANTE, C. V. T.; SANTOS, H. P.; ZANARDI, O. Z. Comportamento vegetativo e produtivo de videiras 'Cabernet Sauvignon' cultivadas sob cobertura plástica. Revista Brasileira de Fruticultura, Jaboticabal, v.30, n.1, p.148-153, 2008.

NAVES, R. L.; TESSMANN, D. J.; GARRIDO, L. R.; SÔNEGO, O. R. Doenças e seu controle. Embrapa Uva e Vinho. 2005. (Sistemas de produção). Disponível em: <http://sistemasdeproducao.cnptia. embrapa.br/FontesHTML/Uva/MesaNorteParana/ doencas.htm/>. Acesso em: 22 abr. 2009.

NOVELLO, V.; PALMA, L. Growing grapes under cover. Acta Horticulturae, Leuven, v.785, n.1, p.353-362, 2008.

SCHIEDECK, G.; MIELE, A.; BARRADAS, C. I N.; MANDELLI, F. Maturação da uva 'Niágara Rosada' cultivada em estufa de plástico e a céu aberto.

Ciência Rural, Santa Maria, v.29, n.4, p.625-633, 1999.

SÔNEGO, O. R.; GARRIDO, L. R.; GRIGOLETTI JÚNIOR, A. Principais doenças fúngicas da videira no Sul do Brasil. Bento Gonçalves: Embrapa Uva e Vinho, 2005. 32p. (Circular Técnica, 56).

SOUZA, R. T. Resposta da cultivar BRS Clara ao manejo da copa e do cacho. Bento Gonçalves: Embrapa Uva e Vinho, 2010. 3p. (Comunicado Técnico, 99). 